\title{
Second Life: A Virtual Learning Center for the Study of Sharks
}

\author{
doi:10.3991/ijet.v6i2.1580 \\ T. Papadamou, C. Gavrilakis, C. Tsolakidis and G. Liarakou \\ University of the Aegean, Rhodes, Greece
}

\begin{abstract}
In this work the educational capabilities of the virtual world Second Life are researched and tested. A virtual world is constructed to support education for sustainable development. The life and characteristics of the shark is studied as this fish has received a lot of negative publicity and is in the danger of extinction. A virtual museum was developed for this purpose. The research question is focused on whether it can be used effectively in a modern classroom and how difficult is for an educator to develop such an application. To achieve that, a number of learning activities were developed, a number of on line questionnaires were issued and a series of virtual meetings were held. Teachers used the application and answered the questionnaires. The entire effort was attempted through Internet exclusively.
\end{abstract}

Index Terms-Education for sustainable development, Second Life, virtual museum.

\section{INTRODUCTION}

Virtual reality (VR) is a three dimensional environment of simulation running on a computer displaying in real time the activities of the users. A virtual environment consists of an index (objects and actors), geometry and physics, that include the perception of objects in depth and through this all senses can be stimulated by an egocentered context [14]. VR is based on Web 2.0 components getting its users deep into interactive environments. According to Bell and Fogler [2] VR is characterized by the development and use of man-made worlds that are organized and governed by a set of rules and regulations. These worlds allow all users to navigate and interact with them. For a user to navigate, there are specific input and output devices that give him/her the experience of a realistic feeling [11]. VR technology progresses with time and users have an increasing feeling that simulation of real life is more realistic. In brief, $\mathrm{VR}$ is an intellectual situation where the subject-user is immersed, partly or totally, in an artificial environment, which can be closely similar to, or vastly different from reality [11].

VR finds uses in many areas among which entertainment and education are very important. The virtual reality has the potential to increase the impact and effectiveness of educational simulation [2]. Learning in a VR environment is a dynamic process determined by the user who sets the aims, changes them at will, and the outcomes of the training process differ from individual to individual [10]. Such an environment provides users with the ability to construct new knowledge through a socio-cultural model which perceives knowledge as being distributed in the virtual world and users learn collaboratively. In relation to conventional forms of education in 'real world', virtual worlds allow participants to experience roles and to do things which would be difficult or impossible to do in the physical world [19], [25]. Moreover, VR is a multisense experience where its illusive nature provides users more than just a simple observation but the ability to participate in an environment and interact with objects and between themselves [9], even if they bring different understandings about how to behave [25].

According to Dreher et al. [8] virtual worlds are of particular pedagogical relevance because in such environments students are prone to explore, participate, discover new knowledge, and develop skills with greater intrinsic motivation and autonomy. A great variety of educational subjects are tested to determine in which VR works efficiently [2]. Specifically, VR is used widely in mathematics and physics science, architecture, medicine, aviation and generally in fields that involve the study of natural phenomena and abstract concepts. Another advantage of virtual reality is that of making what is abstract and intangible to become concrete and manipulable [22]. Further, the application of VR in arts and humanities studies should not be ignored. For example the ability of VR to develop places of educational interest such as historical sites and museums that are not easily accessible in the every day life to students across the world, could be beneficial to social studies, culture and foreign languages [6].

Education for Sustainable Development (ESD) constitutes an interdisciplinary educational field where natural sciences cross inevitably the social sciences and humanities, while its core subject - the environmental issues - are certainly among the most complex learning subjects. Moreover the goals of ESD extend beyond the cognitive domain to cover attitudes, values and skills, while in terms of learning approach, it emphasizes critical and systems thinking, outdoor and student-centered learning strategies. In this context VR can be a beneficial tool for ESD [17], [23].

What was attempted in this project was to bridge the two fields, VR and ESD, to harness the potential of VR, so that a virtual museum for ESD was created. Sotirova [21] comments that the purpose of computers is often to entertain or to create a game or a competition and this is one of the characteristics that a museum has to fulfill; though museums give also emphasis to educational issues, preservation and/or scientific work. Several museums and other cultural institutions have developed applications integrating 3D visualization, decades ago [24]. In recent years, an increasing number of museums use multimedia applications to present their exhibits. Some of them allow users to navigate through exhibits (often by using 360 o panoramas), though there is no true interaction and no exploration of the area that represents the museum [13], 
PAPER

[27]. However only in the last years the progress of technology allowed the development of museums' applications that converge to what today is meant by the term 'virtual reality' (as it was outlined earlier).

The virtual museum was developed in this project by using the software "Second Life" (SL). SL is a web-based virtual world, developed in 2003 by Linden Research Inc., which falls into the category of three-dimensional multiuser virtual environment (3D MUVE), supporting exploration, simulation, role-play, interaction and experimentation via avatars $^{1}$ or 3D self-representations [1], [5], [7]. The users, "residents" of this virtual environment can build objects within their world aiming at e.g. entertainment, retail, academia, advertising and marketing; thus they create their environment [3]. Moreover, the emergence of a market economy, due to the 'linden dollar' currency [1], [3] should not be underestimated, given that it contributes to the development of a new "virtual culture".

Nowadays, Second Life is a very popular and of rapid progress software. Moreover, it has 15 millions registered accounts and an average of 38,000 residents online at any particular moment [26]. Many educational institutions keep their own spaces in this virtual world and offer knowledge in an original way. It is estimated that at least 300 universities around the world teach courses or conduct research in SL [16], though other institutions emerged exclusively within this virtual world. For example Harvard University, Princeton, Kingston, Edinburgh and Drexel, have their Second Life campuses [7], [20]. However, there are powerful pedagogical utilities of Virtual Worlds that are not yet fully evolved or utilized and are thus worthy of consideration [8].

In 2007, when the project started, SL was the most famous and widely spread virtual world in Internet; that was a reason why this particular software was selected. The main reasons for the above selection are closely connected with its pedagogical and technological advantages against other types of virtual reality software. Such key features are: networking, users' interaction and the ability to cooperate for a common task (e.g. to create an object by using their own knowledge), the ability provided to users to create their own experiences, cooperation with a variety of external components and 3D environment. Actually, SL, in educational terms, provides an appropriate space for constructivist learning, as well as a situated learning environment, where its users (i.e. students) can demonstrate the skills and strategies they have acquired [3]. Perhaps the most essential characteristic of this virtual world is that students can interact with others from around the world, expanding their cultural experiences [15]. Within SL, communities of practice are formed, and informal learning takes place. However, it is very crucial for an educator to understand how this new ways of learning and deploying knowledge and skills emerge, so as their learning intervention to make sense [1]. Furthermore, according to Wagner \& Ip [26], virtual worlds in general provide an 'action learning environment' which allow students to enact real ideas against issues while the possible failure has few and inexpensive consequences. Virtual words can be categorized into two major types: purposeful (gamefocused) and general purpose (social-focused). The SL constitutes a typical representative of social-focused vir-

\footnotetext{
${ }^{1}$ Avatar is a representative of a real person in the virtual world.
}

tual worlds, that is to say designed to enable socialization [26].

Till today, several applications linking the VR with ESD have been developed, both internationally and in Greece, though no SL application dedicated to ESD has been reported in the international literature. Thus, the development of this virtual museum constitutes an innovative undertaking. In particular, this museum is dedicated to an important issue of sustainability: the loss of biodiversity.

The subject of this work was the shark, as an endangered fish. Shark is a fish that has evolved over 400 million years, and although it was historically considered of low economic value, today is highly vulnerable to overexploitation. This is mainly due to: directed commercial and recreational activities, the increasing bycatch of fisheries targeting other species, the expanded fisheries in number and size in response to the rapidly increasing demand for shark fins, meat and cartilage, the lack of monitoring and management of the most shark fisheries. Of course it should be mentioned that other biological factors, such as slow growth, late sexual maturity, low fecundity and long life, resulting in low rates of population, also contribute to the depletion of shark populations [4]. Furthermore, one should keep in mind that since the late ' 80 s the shark had a notorious fame as a serial killer. Nowadays, evidence proves that there is yet little knowledge about the life of sharks. So the task of preserving its populations on our planet seems to be tougher than ever before. Some species of sharks are thought to be more endangered than others. For example the great white shark is the species that gained the negative image, and since then it faces the danger of extinction.

Consequently, it is expected that the educational community already has a controversial attitude about sharks. It was believed that providing educators with new, diverse information and pedagogical activities about sharks, teachers and students could develop a new interest about sharks and the wildlife in general. Given the sharks nature, it is very difficult to sustain a pedagogically useful approach to a considerable level using traditional techniques. Second Life's key features provide the ability to know about and study sharks very close.

Further, there was an effort to examine if the study and presentation of an environmental issue, such as species over-exploitation, through this technology would make it more interesting and beneficial.

\section{The Virtual Museum}

According to [23], VR is attracting the interest of educators. For this innovation to become an effective educational tool, educators must become actively involved in its use and development due to its special innovative and immersive nature. Hence, in this work it was attempted to investigate whether a teacher, who isn't a ICTs' expert, can develop a simple learning application in SL. Moreover it was tried to explore how the educational community in Greece and Cyprus responds to such an application. For this purpose, a learning center was developed. It included a virtual museum with a variety of educational material in many formats (sites, videos and data) about the sharks. Despite the advanced capabilities available in SL, the designs were kept to a convenient minimum to encourage the users and keep the virtual world simple. 
At this stage, pupils' involvement in this application was of less interest to the researchers since they considered investigating first the teachers' reaction to this software.

The study of the parameters of the problem and the development of the museum lasted 14 months. In parallel, educators were recruited and were trained to use the virtual world. Later the users were introduced in the virtual museum, and they participated in several simple learning activities during a period of about 1.5 months.

\section{A. Developing the Museum}

In the first stage of exploring Second Life, a wiki was set up to briefly present the major aspects and capabilities of the software. Given that there was no site offering information regarding the operation of SL in Greek, this wiki was needed especially for users that didn't speak English. That wiki was one of the first items that new users would meet in-world and included information on term, definitions and navigation guidance. Language was an essential problem for users in the virtual world since all of them were Greek speaking and the knowledge of their English varied. The users were introduced in specific virtual locations so that the researchers obtain an impression on the "in-world socialization" characteristics of the particular group or users.

In parallel, content for the application was developed. Experimenting with the virtual world, special parts of land called "sandboxes", which were free to be accessed by the users, were created. Finally, a "prim," was found at a private island ${ }^{3}$ that met the needs of the project. It is not easy to find a suitable area for a learning center, given that in the virtual world there are many activities that would be embarrassing for educational centers such as this.

The turning point in this effort was the transition from a simple user to a premium user, i.e. becoming a constructor. This meant new capabilities for the developers both technically and pedagogically. Though, there was a series of wikis developed by Linden Labs and other related companies, that contained all the information necessary to create and navigate a virtual world in English. This massive collection of information could be confusing for the new users.

While investigating the abilities of this particular virtual world, a number of technical issues came up, mainly due to the lack of the network infrastructure of most of the users. Such issues were the difficulty of video displays to work smoothly and directly upon request, as well as the difficulty of interactivity among a large number of users to act simultaneously in-world.

\section{B. Museum's Structure and Operation}

The virtual museum was developed on the owned prim that was located on an island divided into smaller areas. (Fig. 1). Due to the topic of the museum, the location was selected to be by the sea so that the water element is projected at the maximum. The prim consisted of two major sections:

\footnotetext{
${ }^{2}$ Abbreviation of the term 'primitive'. A prim is a single part object. Multipart objects will have multiple primitive parts ('prims'). Virtual physical objects such as cars and even less obvious things such as hair are made out of one or more prims [1].

${ }^{3}$ The virtual world of SL consists of a mainland and hundreds of islands (called 'sims')
}

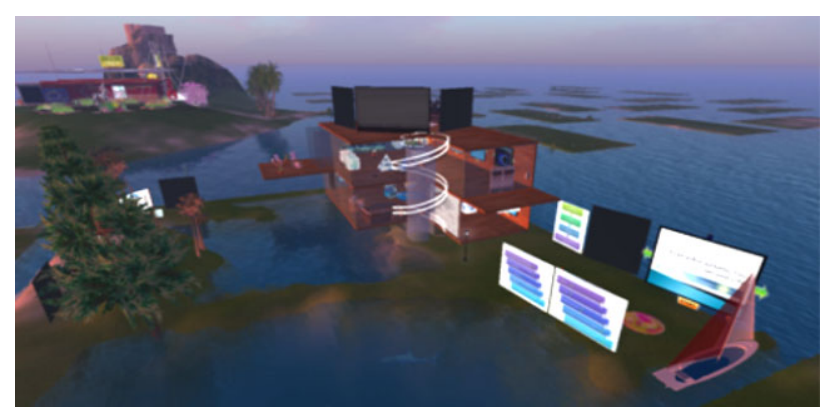

Figure 1. A view from above

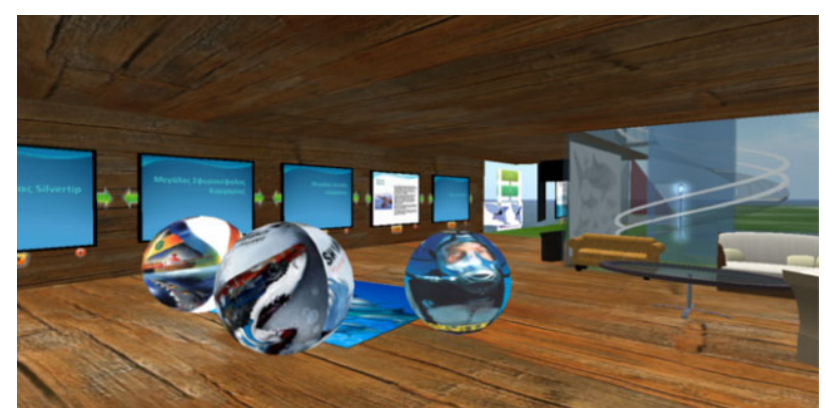

Figure 2. Inside view of the ground floor

a) The 3-floor building.

b) Outside space.

Both were considered as one entity providing visitors with a variety of information and services. It is important to mention that the area was set open to all SL users even if they weren't invited to participate in the project.

The building was separated into three floors, each one having its own purpose and theme.

All of the features mentioned were constructed by using programming on SL's own scripting language. The whole area was supervised by a "beam" (a type of transmitter), programmed to store for the researcher all information necessary about the visits and the visitors.

A. The ground floor (Fig.2) was open to all visitors (although focused to serve primarily school children), and there users were able to discover, read and learn about sharks in various ways. Some characteristic components were:

a) A poster situated at the entrance of the building, showing the size of several species of sharks compared to the size of a diver. This poster was placed to give a first impression to users that the so called 'shark' is not a unique fish but a type of fish, actually representing the superorder 'Selachimorpha' consisted of about 440 species which ranging widely in size, characteristics and habits. For example there is a species of only $17 \mathrm{~cm}$ (Etmopterus perryi) while the largest one is approximately 12 meters (Rhincodon typus). Furthermore, contrary to a common perception that the sharks feed only with big fishes, the Rhincodon typus feeds only on plankton, squid, and small fish.

b) A webpage dedicated to school age children, was constructed in Greek, providing students with simplified information and educational activities about sharks. This specific website was intending to promote the significance of preserving sharks and their habitats as well as the importance of biodiversity. 
The information provided was aiming at the understanding of the role of shark in the food chain, the major threats, the role of human activities and the proposed policies to preserve its populations around the world.

c) A series of PowerPoint presentations that displayed information about the main shark species. In each PowerPoint there was information about shark's biology and many references about the dangers that each species encounters. Emotional pictures were included, although carefully selected so that they did not shock the viewers, i.e. pictures showing massive harvesting of sharks due to finning.

d) Virtual objects that were programmed to work as links to other web pages specialized on sharks, and activities. Specifically, those Flash activities were provided by reliable Greek and international organizations dealing with shark observation and preservation, i.e. Discovery Channel, National Geographic, Animal Planet and Professional Association of Diving Instructors.

e) Further, several quality multimedia applications were selected such as games, quizzes, puzzles, painting activities, video presentations etc.

B. The first floor (Fig.3) was dedicated exclusively to users-teachers. It provided them with more specialized information about sharks and their main threats, again through PowerPoint's and links to other web-pages. It must be noted here that the links were categorized accordingly to their use and content by geometric bodies as follows:

a) Legislation and official reports about sharks used pyramids as links. Such information was obtained from web sites such as that of the EU and governmental or non-governmental organizations. The information provided was aiming to inform teachers about shark's preservation, laws and conventions concerning its protection.

b) Educational tools, search engines or development tools in the virtual world used cubes as links. The purpose of those tools was to assist users to get over the premium status and become a constructor him/herself. Tools that are widely used, like YouTube, Wikis, Wikipedia and Linden Labs' own sites were embedded in our learning center to make new users" "life" into this world as easy as possible.

c) EDS sites and portals and Non Governmental Organisations, used spheres as links. Several quality sites were included, aiming at providing teachers with basic knowledge regarding applications of ESD in schools. Those sites provide educational applications which could be implemented per se or properly adapted by teachers according to the needs of their classes.

The first floor area offered information only for educators and it had the option to lock, not permitting the entrance to pupils.

C. The second floor (Fig.4) was an open space and an amphitheatre for lectures and meetings. There was room for 25 persons - avatars to actually sit and take part in a lecture given e.g. by the museum's guide, a teacher etc. This amphitheatre had also 3 large video-wall displays

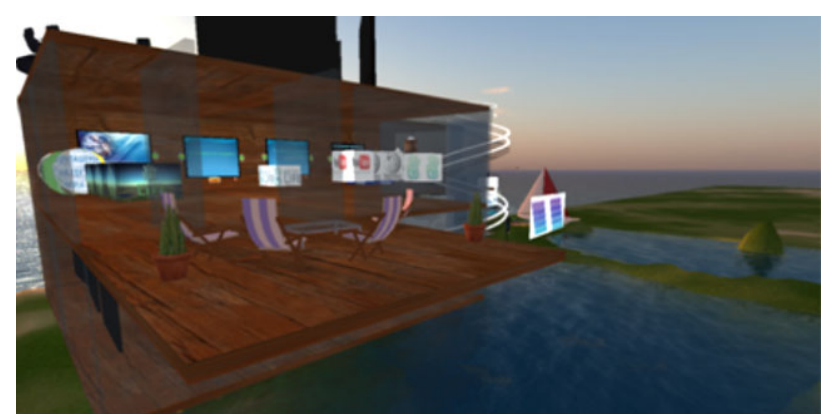

Figure 3. First floor is the teachers' space

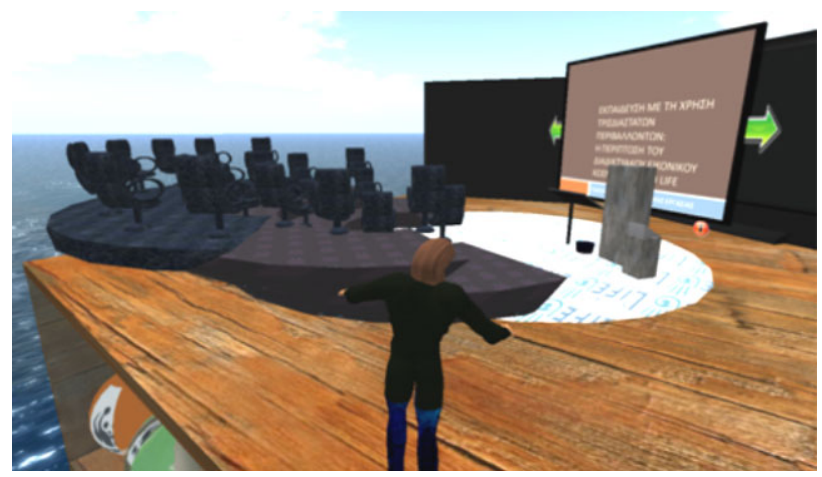

Figure 4. Amphitheater in the second floor

that they were used for projecting PowerPoint presentations, web pages and videos. Moreover, the capability for connection to Moodle learning management system was installed but was not used, as it was considered too difficult to handle by the users at this stage in the project.

D. Finally, the outdoor section included four main features:

a) The entrance area, where some information was available to users as a welcome note, PowerPoint presentations etc.

b) The outside scenery that was constructed to serve the main theme of the project i.e. there were spaces filled with 3D and 2D models of shark species.

c) The evaluation corner, where the two in-world questionnaires (see below) were located.

d) Video walls scattered throughout the outdoor space, so that users had the ability to watch any material used in the amphitheater, not having to be there constantly.

\section{EVALUATION}

The project was evaluated by users that they were teachers and education departments' students. Given the nature of this software, to assess the usability of this application, both quantitative and qualitative inquiry methods were used [12], [18]. Hence, it was attempted to report users' acquisition of knowledge in the world. Also their impression and comments regarding SL and the museum were recorded by using a kind of "virtual participative observation".

Following the first period of testing the software and before involving the users with the software, a questionnaire was developed to:

a) Identify the profile of each individual user, and 
PAPER

b) Report the opinion of the users about virtual worlds and especially the SL.

This questionnaire was addressed by e-mail, to two major groups of users, (a) to a group in the social network "Facebook" and (b) to the mailing list of the wiki that was set up especially for this purpose, a total of 300 teachers and students in the two countries (Greece and Cyprus). It was decided to use these two ways of communication to ensure that those responding to the invitation would have adequate skills to use ICTs and the Internet. Out of 300 who received the questionnaire, 101 answered it.

In detail, $54.46 \%$ stated that they are good users and $30.69 \%$ stated that they are experts in using ICT. A good part of them $(86.14 \%)$ answered that they use the Internet more than 5 hours/week. Moreover, $62 \%$ of the sample is using the web for educational purposes. They use the Internet as a means of communication (19.74\%), information source $(18.70 \%)$, knowledge source $(18.70 \%)$, professional tool $(14.81 \%)$ entertainment tool (13.51\%), and other miscellaneous applications $(14.55 \%)$, while all of them answered positively that the Internet could be an educational medium. With respect to Second Life, a remarkable share of participants $(38.6 \%)$ stated that they ignore the existence of this particular world, while $49.5 \%$ stated that they have little knowledge about it. Only $10.9 \%$ stated that they can use SL in a sufficient level. This is probably due to the very little promotion SL has in Greece and Cyprus. However, $81.2 \%$ answered that a virtual space could well be an educational tool.

Furthermore, the users were provided with all the basic information necessary to access the virtual location of the project. They were asked to download two text files containing installation guidelines and a user's manual to help them with their whereabouts in SL.

A group of 26 people, out of 101, used the virtual world. To familiarize with the software and to sort out any problems before visiting the museum, the users attended a number of meetings inside the virtual world. Those meetings helped the trainees and also the trainers to acquire a deeper understanding of the parameters and technical issues of the project.

Despite training, users had difficulties entering the museum's space and they asked for help. They used the virtual world for a period of 1.5 month in total, yet their action inside the virtual world was very limited as indicated by system statistics of SL.

While in the virtual museum, there were some interesting responses recorded. Most of them were positive comments, such as "I don't believe that such thing exists! It is beautiful!", or there were questions on how would someone navigate more easily in the virtual world, such as "Could I enter it whenever I want to?" or "Should I read all of the info?". Due to the fact that it was the first time for most of them entering a virtual world, there was anxiety and awkwardness. Commends and queries such as "What should I do next?", "Lets see what's that!" or "Really? I didn't knew that!" were frequent. All of the users enjoyed the ability to fly, which was the only way to move from level to level in the learning center. The users also enjoyed the ability to create their own avatars and customize their appearance.

In addition, the museum's evaluation process included two questionnaires: a) In the learning center, the users had the opportunity to access material about the sharks on various occasions and in many formats. At the end of their virtual stay, they were asked to test their newly acquired knowledge on a questionnaire, the "Shark Quiz", at the "Evaluation Corner" that was set up especially for this reason. This quiz was answered by all of the 26 participants and had an $82 \%$ of success (the average value of correct answers out of 16 relevant questions).

b) After completing their visit to the museum, participants were issued with a new questionnaire, which recorded their impressions about the entire experience. The questions referred to the quality of the virtual world and the SL in general. The answers of the questionnaire were of "Yes/No" type and were forwarded to the researcher's email address. In particular, users were asked to state whether they: enjoyed the navigation, acquired further knowledge, would like to participate again to such an educational application, are interested in developing their own virtual world, feel more familiar with the virtual spaces and, finally, consider that SL can be useful for the educational practice. Positive answers, regarding the quality of services provided, were in excess of $90 \%$.

\section{CONCLUSIONS - DiscuSSION}

The prospect of using 3D environments as an educational tool therefore the possibility of widening the variety of educational means was examined with the use of the presented application. This issue is very important for the contemporary school, which has to deal with complex and multidimensional topics, such as environmental issues. In this context, the virtual world 'Second Life' has been used to deal with Education for Sustainable Development and specifically, the loss of biodiversity. A virtual learning center for the study of sharks, as an endangered species, was developed by teachers that weren't ICTs' experts and this application was evaluated by teachers and students. During the phase of developing the center and also during the test period, both capabilities and limitations of the SL were revealed, in pedagogical and technical terms. Although the limited number of participants in this study doesn't allow the generalization of the conclusions, the results offer an outline of critical pedagogical and technical dimensions of SL.

After having tested consistently, one can argue that SL is a virtual world providing both developers and users with a wide range of technological advantages. For instance, someone attempting to develop educational applications can take advantage of many camera views for a better understanding of what is happening in-world, many constructing and landscape reforming tools, an editable programming language, communication tools and inventory saving options (items and locations) etc. In addition, the users of this virtual world (when using avatars) have a variety of possible moves, gestures and communication forms.

However, one of the most important features available in SL is that of in-world interacting, even though this option has not been utilised to the desirable extend. In fact, collaborative construction of knowledge and user interaction, are fields that traditional education has a lot to progress. In addition, the $3 \mathrm{D}$ aspect of SL in combination with its networking ability and animation, allow the 
teacher to approach a subject through different perspectives and realism that in another way would probably be impossible. Education for Sustainable Development deals with various such subjects i.e. endangered species, less known ecosystems, the world hunger etc. SL also proved that it can create the conditions for the development of communities of practice. Such a community has been initiated in the context of this project; though it is expected to work better when the learning centre reaches full operation with more material and better facilities.

Such pedagogical advantages have contributed so that large percentage of the participants succeeded in the knowledge test about sharks and expressed their satisfaction with SL as an educational tool, according to the results of the museum's evaluation.

On the other hand, it should be noted that, although not impossible, it was quite difficult for non-specialists in ICT to develop such an educational application. Moreover, it was relatively hard for users, even after a series of training meetings, to navigate in the virtual world and to use the services of the museum without having a minimum support. This problem is partially reflected in the limited number of participants who entered the virtual museum, in relation to those participated in the initial web-based survey concerning their relation with ICTs and the SL. In fact, several difficulties arose when the new users attempted to come into the virtual world. For instance, they considered some of its features and menus as sophisticated. Further, the massive flow of information given inworld, became a frontier to discovering all features of SL, while issues concerning incompatibility with other web services were reported.

The technological dimension presented most problems from the points of view of hardware, software and connectivity requirements. Though, it is considered that such constraints are to be solved in the near future as technology progresses and is more widely spread throughout the world, probably by using geographically distributed servers [8]. Of course, the technology issue is intensified by the fact that the application is running in different countries with different ICT penetration in their society i.e. Greece and Cyprus.

However, the problems reported were not discouraging in continuing this effort. As the culture to use it increases, the prospect for reaching the maximum potential of this virtual world for educational purposes is yet to come. SL has great potential to contribute to the improvement of learning process in general and to ESD.

The virtual museum for sharks is going in the near future to integrate more SL's supportive features that could enhance its function, and its learning approach in the context of ESD. For instance, a helpdesk, a FAQs spot, glossaries or even a "guide user" for in-world assistance, could facilitate the implementation of educational activities, as it was made clear during the evaluation. In addition, more activities are needed that require mainly collaborative work and experiential learning so as to increase interaction. For example, a virtual field trip could be planned, including both individual and collective activities about sharks.

Furthermore, tools for statistical analysis regarding the activities of users in-world need to be integrated. Also, an adequately long phase concerning a preliminary prepara- tion of participants with regard to SL should be considered.

Summing up, Second Life is an application that deserves much attention of researchers in the fields of Education for Sustainable Development and Information and Communication Technologies, so that innovative educational training schemes could be developed.

\section{REFERENCES}

[1] D. Bell, "Learning from Social Life," British Journal of Educational Technology, vol. 40, no. 3, pp. 515-525, 2009. doi:10.1111/j.1467-8535.2009.00943.x

[2] J.T. Bell and H.S. Fogler, "Recent Developments in Virtual Reality Based Education," in American Society for Engineering Education Annual Conference, Washington DC, 1996.

[3] M.L. Burgess, J.R. Slate, A. Rojas-LeBouef and K. LaPrairie, "Teaching and Learning in Second Life: Using the Community of Inquiry (CoI) Model to Support Online Instruction With Graduate Students in Instructional Technology," The Internet and Higher Education, vol. 13, no. 1-2, pp. 84-88, 2010. doi:10.1016/ j.iheduc.2009.12.003

[4] M. Camhi, S. Fowler, J. Musick, A. Bräutigam and S. Fordham, Sharks and their Relatives: Ecology and Conservation. Occasional Paper of the IUCN Species Survival Commission No. 20. Oxford: IUCN, 1998.

[5] J. Clarke, C. Dede, D.J. Ketelhut and B. Nelson, “A design-based research strategy to promote scalability for educational innovations," Educational Technology, vol. 46, no. 3, pp. 27-36, 2006.

[6] B. Dalgarno, J. Hedberg and B. Harper, "The Contribution of 3D Environments to Conceptual Understanding," in Winds of change in the sea of learning: Charting the course of digital education, Proceedings of the 19th Annual Conference of the Australasian Society for Computers in Learning in Tertiary Education, A. Williamson, C. Gunn, A. Young and T. Clear, Eds. Auckland, NZ: UNITEC Institute of Technology, 2002, pp. 149-158.

[7] D.E. Descy, "All Aboard the Internet: Second Life," TechTrends, vol. 52, no. 1, pp. 5-6, 2008.

[8] C. Dreher, T. Reiners, N. Dreher and H. Dreher, "Virtual Worlds as a Context Suited for Information Systems Education: Discussion of Pedagogical Experience and Curriculum Design with Reference to Second Life," Journal of Information Systems Education, vol. 20, no. 2, pp. 211-224, 2009.

[9] R. Earnshaw, H. Jones and M. Gigante, Virtual Reality Systems. Orlando, Fl: Academic Press, 1993.

[10] M. Fokides and C. Tsolakidis, "A Theoretical and a Technical Framework for the Development of Virtual Reality Educational Applications," in 6th International Workshop on Interactive Computer Aided Learning, Villach, Austria, 2003.

[11] E. Fokides and C. Tsolakidis, "Virtual Reality in Education: A Theoretical Approach for Road Safety Training to Students. European Journal of Open," Distance and E-Learning, issue 2008/II, 2008.

[12] J. Hom. (2010, January 18). Usability Methods Toolbox. Available: http://jthom.best.vwh.net/usability/.

[13] G. Kavouklis and C. Tsolakidis "The Use of Virtual Reality for Pedagogical Visits in Museums and Galleries: the Case of 360 Panoramas," in EDEN 2009 Annual Conference 'Innovation in Learning Communities', Gdansk, Poland, 2009.

[14] C.E. Loeffler and T. Anderson, Eds, The Virtual Reality Casebook. New York: Van Nostrand Reinhold, 1994.

[15] L. McGregor and M. Reeser, "Removing Boundaries and Increasing Student Engagement through Virtual World Platforms," Diverse Issues in Higher Education, vol. 26, no. 20, p. 19, 2009.

[16] P. Michels. (2010, January 18). Universities Use Second Life to Teach Complex Concepts. Government Technology. Available: http://www.govtech.com/gt/252550.

[17] T. Mikropoulos, A. Chalkidis, A. Katsikis and P. Kossivaki, "Virtual Realities in Environmental Education: the Project LAKE," Education and Information Technologies, vol. 2, no. 2, pp. 131142, 1997. doi:10.1023/A:1018648810609

[18] J. Nielsen, Usability Engineering. USA: Academic Press, 1993. 
[19] N.A. Rappa, D.K.H. Yip and S.C. Baey, "The role of teacher, student and ICT in enhancing student engagement in multiuser virtual environments," British Journal of Educational Technology, vol. 40, no. 1, pp. 61-69, 2009. doi:10.1111/j.1467-8535. 2007.00798.x

[20] SimTeach Wiki (2010, January 18). Institutions and Organizations in SL. Available: http://www.simteach.com/wiki/index.php?title= Institutions and Organizations in SL

[21] K. Sotirova, "Edutainment games - Homo Culturalis vs. Homo Ludens," in International Conference MASSEE 2003 - Review of the National Center of Digitization, Serbia and Montenegro, 2004, pp. 84-98.

[22] N. Strangman, T. Hall and A. Meyer, Virtual reality/simulations with UDL. Wakefield, MA: National Center on Accessing the General Curriculum, 2003.

[23] G.L., Taylor and J.F. Disinger, "The Potential Role of Virtual Reality in Environmental Education," The Journal of Environmental Education, vol. 28, no. 3, pp. 38-43, 1997. doi:10.1080/00958964.1997.9942828

[24] I. Tjostheim and J. Lous, "Attracting Visitors- Using Computer Games Technology to Build a VR-Museum," in Information and Communication Technologies in Tourism 2006 - Proceedings of the International Conference in Lausanne, M. Hitz, M. Sigala and J. Murphy, Eds. Wien: Springer-Verlag, 2006, pp.44-54.

[25] P. Twining, "Exploring the educational potential of virtual worlds - Some reflections from the SPP," British Journal of Educational Technology, vol. 40, no. 3, pp. 496-514, 2009. doi:10.1111/j.14678535.2009.00963.x

[26] C. Wagner and R.K.F. Ip, "Action Learning with Second Life - A pilot Study," Journal of Information Systems Education, vol. 20, no. 2, pp. 249-258, 2009.

[27] N. Zouboula, M. Fokides and C. Tsolakidis, "Educational Uses of Virtual Reality: Constructing a VR Museum," in 11th International Conference on Interactive Computer Aided Learning, Villach, Austria, 2008.

\section{AUTHORS}

Tryfonas Papadamou is a qualified primary school teacher. After completing his undergraduate degree as a primary school teacher in the University of the Aegean, he received the M.Sc. Educational Sciences - Education with the use of ICT. His research interests combine both technological and environmental aspects. In specific his main interests include the study of $3 \mathrm{D}$ environments in education, internet technologies and Education for Sustainable Development, as well.

Costas Gavrilakis, Ph.D., is a researcher at the University of the Aegean. He studied Environmental Studies before receiving M.Sc. in Environmental Policy and Management and Ph.D. in Environmental Education. His research interests involve EE program planning as well as information and communication technologies in EE. Together with Georgia Liarakou, he is responsible for the content of the Greek portal of EE material www.envedu.gr.

Costas Tsolakidis is an assistant professor at the Department of Primary Education of the University of the Aegean in Greece. He teaches information technology related subjects. His academic interests include distance learning, using information technology as an instrument for development in rural areas, multigrade teaching, educational applications for virtual reality. He was involved in a number of EU and Greek funded projects.

Georgia Liarakou is an assistant professor at the Department of Primary Education of the University of the Aegean in Greece. Her academic subject involves theory and practice of Environmental Education and Education for Sustainable Development. Her research has focused on the investigation of teachers, students and pupils' perceptions of several concepts and processes regarding Environmental Education. Currently, she is working on the research topic of Education for Sustainable Development.

Received March $2^{\text {nd }}, 2011$. Published as resubmitted by the authors May $31^{\text {st }}, 2011$. 